\title{
Kidney Cancer cM0 TNM Finding v7
}

National Cancer Institute

\section{Source}

National Cancer Institute. Kidney Cancer cMO TNM Finding v7. NCI Thesaurus. Code C89299.

Kidney cancer without evidence of distant metastasis. (from AJCC 7th Ed.) 